\title{
Composites of UHMWPE fiber reinforced PU/epoxy grafted interpenetrating polymer networks
}

\author{
S.P. Lin ${ }^{\text {a }}$, J.L. Han ${ }^{\text {c }}$, J.T. Yeh ${ }^{\text {d }}$, F.C. Chang ${ }^{\text {e }}$, K.H. Hsieh ${ }^{\text {a,b,* }}$ \\ a Institute of Polymer Science and Engineering, National Taiwan University, Taipei 106, Taiwan \\ ${ }^{\mathrm{b}}$ Department of Chemical Engineering, National Taiwan University, Taipei 106, Taiwan \\ ${ }^{\mathrm{c}}$ Department of Chemical and Materials Engineering, National I-Lan University, I-Lan 260, Taiwan \\ ${ }^{\mathrm{d}}$ Department of Textile Science, Nanya Institute of Technology, Taoyuan 414, Taiwan \\ e Department of Applied Chemistry, National Chiao Tung University, Hsin-Chu 300, Taiwan
}

Received 11 July 2006; received in revised form 28 November 2006; accepted 4 December 2006

Available online 2 February 2007

\begin{abstract}
Several polyurethane-modified epoxy resins (PU/DGEBA-g-IPNs) were synthesized and characterized through a series tests, including differential scanning calorimetry and mechanical property measurements, such as tensile, Izod, bending and shear strengths were investigated in the study. The PU/DGEBA-g-IPNs and neat DGEBA as matrices for UHMWPE fiber-reinforced and aramid fiber-reinforced composites were prepared for comparison of their mechanical properties. The degree of plasma treatment, the polyurethane content, and the type of polyol in the polyurethane within the matrix of the composite were investigated through mechanical and bulletproof testing.
\end{abstract}

(C) 2006 Elsevier Ltd. All rights reserved.

Keywords: Epoxy (DGEBA); Polyurethane (PU); Ultrahigh-molecular-weight polyethylene (UHMWPE) fibers; Interpenetrating-polymer-network (IPN); Plasma surface treatment; Bulletproof testing

\section{Introduction}

Fiber-reinforced polymer composites are used widely in materials applications. Several kinds of fibers have been applied as reinforcing materials, including carbon fibers [1,2], glass fibers [3-6], aramid fibers, and ultrahigh-molecular-weight polyethylene (UHMWPE) fibers [7,8]. UHMWPE fibers

\footnotetext{
* Corresponding author. Address: Institute of Polymer Science and Engineering, National Taiwan University, Taipei 106, Taiwan. Tel.: +886 23366 5314; fax: +88623366 5237 .

E-mail address: khhsieh@ntu.edu.tw (K.H. Hsieh).
}

possess many advantageous properties, including light weight, high tensile strength and tensile modulus, and good resistance toward chemicals and wear, but also several drawbacks, such as low surface energy and poor creep and heat resistance.

There are many advantages for using epoxy resin in industrial applications, including its good mechanical and dielectric properties, high processability, low shrinkage, and thermal and chemical resistance. Many researchers have attempted to prepare composites from epoxy resin and other materials; such modified composites include cross-linked structures [9], simultaneous interpenetrating polymer networks (IPNs), semi-IPNs, and sequential IPNs. 
The properties of the interface between the UHMWPE fibers and the polymer matrix are important factors determining the mechanical properties of UHMWPE fiber-reinforced composites. Many researchers have attempted to improve the surface properties of UHMWPE fibers through such procedures as chemical grafting [10], acid etching [11], corona discharging [12], plasma deposition [13], and treatment under high-energy laser and UV irradiation [14].

In this study, we synthesized 10 sets of PU/ DGEBA-g-IPN resins possessing various PU contents to investigate their thermal properties (e.g., $T_{\mathrm{g}}$ values), through DSC analysis, and their mechanical properties, including tensile strength, tensile modulus, Izod impact strength, shear strength, and bending strength.

For the manufacture of the UHMWPE fiberreinforced composites, six kinds of PU/DGEBA-gIPN matrices with two kinds of UHMWPE fiber reinforcements (i.e., untreated and plasma-treated UHMWPE fibers) were prepared and then the mechanical properties of the various reinforced composites were investigated. SEM observations of the fracture surfaces demonstrated the improved interfacial adhesion and wet-out properties. The bulletproof properties of the UHMWPE fiber/PU and aramid fiber/PU composites of different thickness were also investigated in the study.

\section{Experimental}

The materials used are listed in Table 1. Epoxy resin (DGEBA; diglycidyl ether of bisphenol A; $\mathrm{EEW}=186$ ) and various polyols, including PBA 700, 1000, and 2000 and PPG 2000, were heated and degassed under vacuum overnight prior to use.

\subsection{Preparation of polyurethane prepolymer and PUIDGEBA-grafted-IPN resins (PUIDGEBA-g-IPNs)}

The isocyanate-terminated polyurethane (PU) based on PPG 2000 polyol was prepared by reacting 2 equiv. of MDI with 1 equiv. of the polyol (PPG 2000) under a dry nitrogen atmosphere at $70{ }^{\circ} \mathrm{C}$. The synthesis reaction extent was determined through FTIR spectroscopic analysis.

The isocyanate-terminated polyurethane (PU) was prepared by reacting 2 equiv. of MDI with 1 equiv. of a polyol (PBA 700, 1000, or 2000). The reaction, which was performed under a dry nitrogen atmosphere at $70^{\circ} \mathrm{C}$, was deemed complete when the isocyanate content $(\% \mathrm{NCO})$ reached a constant value, as determined through by FTIR spectroscopic analysis. At that point, DGEBA (various equivs.) was added and the components mixed thoroughly. The molecular structures of the PU/ DGEBA-g-IPNs are illustrated as follows:
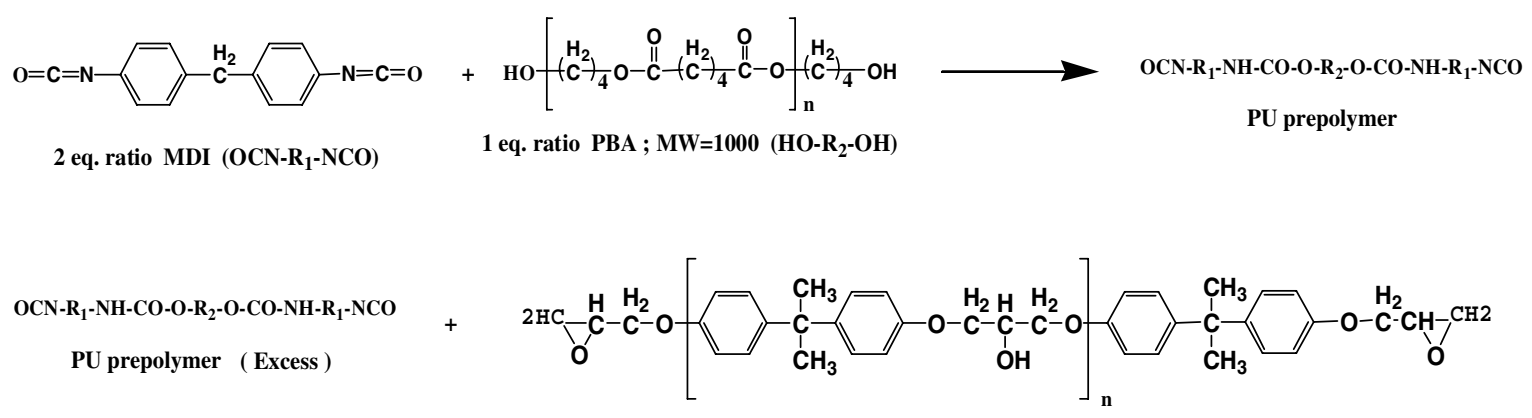

Epoxy Resin (DGEBA)

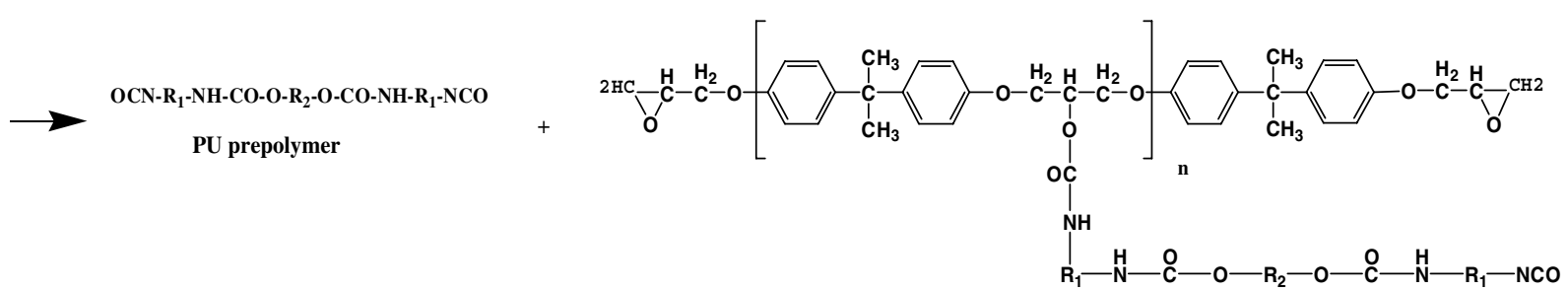


Table 1

Experimental materials

\begin{tabular}{|c|c|}
\hline Designation & Description \\
\hline UHMWPE fiber & Spectra@900 Denier 1200 \\
\hline Aramid fiber & Technora@T-200 \\
\hline Epoxy resin & $\begin{array}{l}\text { DGEBA; diglycidyl ether of bisphenol A; } \\
\text { EEW = } 186 \text { (Dow Chem.) }\end{array}$ \\
\hline $\begin{array}{r}\text { PBA 700, 1000, } \\
2000 \text { (polyol) }\end{array}$ & $\begin{array}{l}\text { Poly(tetramethylene adipate)glycol; } \\
\text { MW }=700,1000,2000 \text { (Tai Gin Co., } \\
\text { Taiwan) }\end{array}$ \\
\hline PPG 2000 (polyol) & $\begin{array}{l}\text { Poly(oxypropylene)glycol; MW }=2000 \\
\text { (Tai Gin Co., Taiwan) }\end{array}$ \\
\hline MDI & $\begin{array}{l}\text { 4,4'-Diphenyl methane diisocyanate (TCI } \\
\text { Chem.) }\end{array}$ \\
\hline 1,4-BD & 1,4-Butanediol (Acros Organics) \\
\hline TMP & Trimethylolpropane (Acros Organics) \\
\hline TDMP & $\begin{array}{l}\text { 2,4,6-Tri(dimethylaminomethyl)phenol } \\
\text { (Jin-Men Chem. Co., Taiwan) }\end{array}$ \\
\hline Acetone & 2-Propanone (Acros Organics) \\
\hline
\end{tabular}

\subsection{Curing the PUIDGEBA-g-IPN resins}

The TDMP curing agent ( $3 \mathrm{phr}$ based on the content of PU/DGEBA-g-IPN resin), a homogeneous solution of 1,4-BD and TMP (4:1 ratio), and a PU/DGEBA-g-IPN system (various PU contents) were added individually into a dry plastic beaker and then thoroughly mixed and drafted to eliminate the bubbles produced during the course of agitation. The individual mixtures were then poured into an aluminum mold coated with Teflon and pressed at $100 \mathrm{~kg} / \mathrm{cm}^{2}$ and $75^{\circ} \mathrm{C}$ for $1 \mathrm{~h}$ and then post-cured at $150 \mathrm{~kg} / \mathrm{cm}^{2}$ and $90^{\circ} \mathrm{C}$ for $2 \mathrm{~h}$.

\subsection{Surface modification of UHMWPE fiber through plasma treatment}

The UHMWPE fiber was immersed in a nonpolar solvent (benzene), a polar solvent (ethanol), and distilled water individually to clean the surface of the fiber before plasma treatment [15].

The plasma treatment apparatus, which was custom-designed by JADE Power Enterprise Co., Ltd., Taiwan, consisted of a chamber (30-cm diameter), a plasma generator, and a power supply. Four plasma treatment times $(1,5,10$, and $20 \mathrm{~min})$ were selected at a constant power $(200 \mathrm{~W})$. After plasma treatment, the fiber was exposed to the ambient atmosphere for its reaction with oxygen.
2.4. Preparation of UHMWPE fiber-reinforced PUI $D G E B A-g-I P N$ (and PU) composites and aramid fiber-reinforced $P U$ composites

The drum-type winding machine, which was custom-designed, consisted of a resin tank with a heater, a winding drum, and two pumps. These two pumps dominated the speeds with two directions (parallel and vertical to the winding direction) to control the winding thickness of the pre-pregs.

The TDMP curing agent ( $3 \mathrm{phr}$ based on the content of PU/DGEBA-g-IPNs), a homogeneous solution of 1,4-BD and TMP (4:1 ratio), and a PU/ DGEBA-g-IPN (various PU contents) were mixed into the resin tank of the drum-type winding machine. Acetone was used to dilute the PU/ DGEBA-g-IPN systems to facilitate impregnation of the UHMWPE fibers in the drum-type winding machine. After the pre-pregs were wound up, they were heated for $30 \mathrm{~min}$ at $60{ }^{\circ} \mathrm{C}$ in an oven to remove the acetone. Unidirectional UHMWPE fiber/PU/DGEBA-g-IPN composites (packing angle: $0^{\circ}$ ) and cross-ply UHMWPE fiber/PU/ DGEBA-g-IPN composites (packing angle: $0^{\circ}, 90^{\circ}$ ) [or unidirectional and cross-ply aramid fiber reinforced composites] that had (or had not) been subjected to plasma fiber surface treatment were fabricated using eight plies (parallel or perpendicular) of manufactured pre-pregs; the dimensions of the compression mold were $200 \times 200 \times 1 \mathrm{~mm}$ (length $\times$ width $\times$ thickness). The pre-pregs were stacked and compression-molded at $100 \mathrm{~kg} / \mathrm{cm}^{2}$ and $75^{\circ} \mathrm{C}$ for $1 \mathrm{~h}$ prior to post-curing at $150 \mathrm{~kg} /$ $\mathrm{cm}^{2}$ and $90^{\circ} \mathrm{C}$ for $2 \mathrm{~h}$.

The preparation of PU prepolymer matrix composite was the same as mention before. A homogeneous solution of 1,4-BD and TMP (4:1 ratio) and $\mathrm{PU}$ prepolymer were mixed into the resin tank of the drum-type winding machine. Cross-ply UHMWPE fiber/PU composites and aramid fiber/ PU composites (packing angle: $0^{\circ}, 90^{\circ}$ ) were fabricated using 48 perpendicular plies of manufactured pre-pregs [dimensions of the compression mold: $200 \times 200 \times 5 \mathrm{~mm}$ (length $\times$ width $\times$ thickness) $]$ and 96 perpendicular plies of manufactured pre-pregs $[200 \times 200 \times 10 \mathrm{~mm}$ (length $\times$ width $\times$ thickness) $]$. The pre-pregs were stacked and compression molded at $100 \mathrm{~kg} / \mathrm{cm}^{2}$ and $75^{\circ} \mathrm{C}$ for $1 \mathrm{~h}$ and then post-cured at $150 \mathrm{~kg} / \mathrm{cm}^{2}$ and $90{ }^{\circ} \mathrm{C}$ for $2 \mathrm{~h}$.

For mechanical testing, the various composite specimens were cut into smaller sizes using a hydraulic power cutting machine (UHO Enterprise 
Corporation, Taiwan). The fiber content of the cured UHMWPE fiber reinforced composites were obtained by etching off the resin in $80 \% \mathrm{HNO}_{3}$ solution under reflux for $4 \mathrm{~h}$ and then recording the weight loss [16].

\subsection{Testing methods}

Infrared spectra were recorded using a BIO-RAD FTS-40 FT-IR spectrophotometer operated at $4 \mathrm{~cm}^{-1}$ resolution. Differential scanning calorimetric (DSC) analyses were performed using a DuPont 2010 operated at a heating rate of $10^{\circ} \mathrm{C} / \mathrm{min}$ over the temperature range $40-180^{\circ} \mathrm{C}$. Morphological studies were performed using a Tescan $5136 \mathrm{MM}$ scanning electron microscope (SEM).

The tensile strengths, Izod impact strengths, bending strengths, and shear strengths of the various PU/DGEBA-g-IPN resin samples were measured according to the ASTM-638, ASTM-256, ASTM-790, and ASTM-2344 protocols.

The stress-strain properties of the various UHMWPE fiber-reinforced composites were measured according to the ASTM-D3039 protocol. The falling-weight impact strength analyses of the various UHMWPE fiber-reinforced composites were performed using a machine that had been custom designed according to the ASTM-6264 protocol. Bulletproof testing of the various UHMWPE- and aramid-fiber-reinforced composites was performed under National Institute of Justice ballistic standards (NIJ 0108.01 IIA and NIJ 0108.01 IIIA).

\section{Results and discussion}

\subsection{FTIR spectroscopic analysis}

Fig. 1 displays FTIR spectra of the synthetic PU/ DGEBA-g-IPNs. The broad peak of the $-\mathrm{OH}$ groups $\left(3500 \mathrm{~cm}^{-1}\right)$ of the PBA 1000 polyol is evident in Fig. 1a. The spectrum of the sample obtained after purging with dry nitrogen gas - to remove both air and moisture from the reaction kettle - and then mixing in 2 equiv. of MDI and 1 equiv. of PBA 1000 is presented in Fig. 1b. During the middle stages of the reaction, the peak intensity of the $-\mathrm{OH}$ groups $\left(3500 \mathrm{~cm}^{-1}\right)$ gradually disappeared, the peak intensity of the $-\mathrm{NCO}$ groups $\left(2270 \mathrm{~cm}^{-1}\right)$ reduced to half of its original value (based on the peak of the 1,4disubstituted benzenes, $840 \mathrm{~cm}^{-1}$ ). The reactions of the various polyols (PBA 700 and 2000) and MDI were quite similar, as suggested by the results pre-

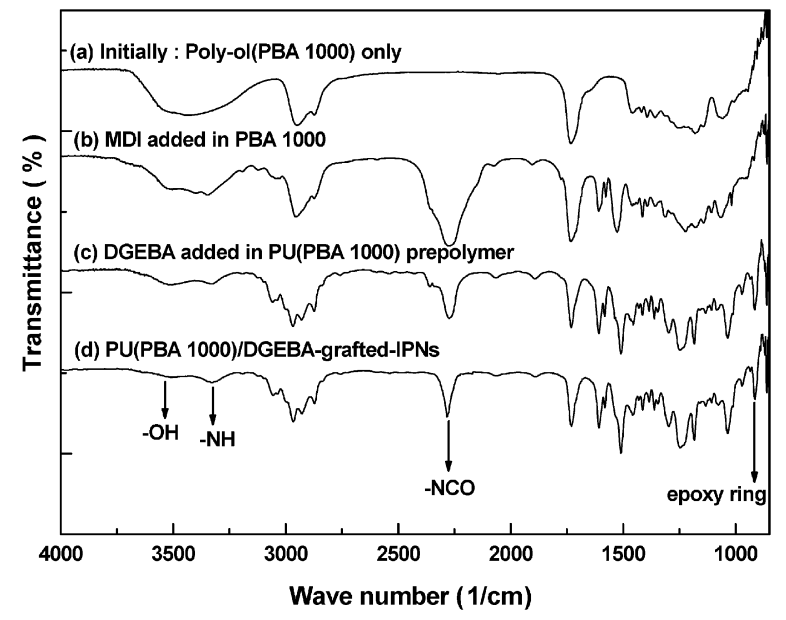

Fig. 1. FTIR spectra recorded at four different reaction stages during the synthesis of PU/DGEBA-g-IPNs. (a) Initially: PBA 1000 only; (b) MDI added in PBA 1000; (c) DGEBA added in PU(PBA 1000) prepolymer; (d) PU(PBA 1000)/DGEBA-graftedIPNs.

sented in Fig. 1c. Finally, DGEBA was added to the reaction systems. During the final stages the peak intensity of the residual $-\mathrm{NCO}$ groups $\left(2270 \mathrm{~cm}^{-1}\right)$ continued to reduce until finally it remained constant, as indicated in Fig. 1d.

Fig. 2 displays the FTIR spectra recorded during the synthesis of the PU prepolymer based on the PPG 2000 polyol. The broad peak of the $-\mathrm{OH}$ groups $\left(3500 \mathrm{~cm}^{-1}\right)$ of PPG 2000 are identified in Fig. 2a. Fig. $2 b$ presents the spectrum obtained after 2 equiv. of MDI and 1 equiv. of PPG 2000 had been

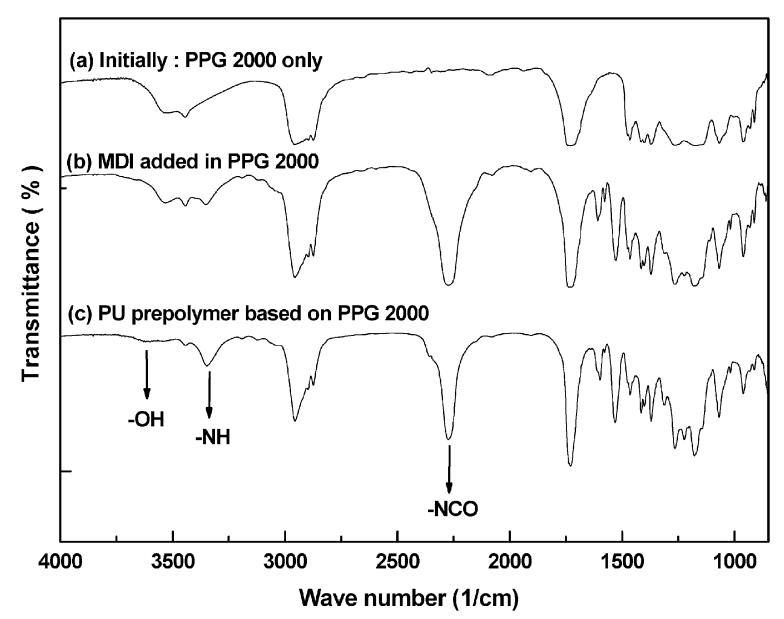

Fig. 2. FTIR spectra recorded at three different reaction stages during the synthesis of the PU prepolymer incorporating PPG 2000. (a) Initially: PPG 2000 only; (b) MDI added in PPG 2000; (c) PU prepolymer incorporating PPG 2000. 
mixed in the reaction kettle and purged with dry nitrogen gas to remove both moisture and air from the reaction kettle. During the reaction period, the peak intensity of the $-\mathrm{OH}$ groups $\left(3500 \mathrm{~cm}^{-1}\right)$ gradually disappeared, the peak intensity of the $-\mathrm{NCO}$ groups $\left(2270 \mathrm{~cm}^{-1}\right)$ reduced to half of its original value (based on the peak of the 1,4-disubstituted benzenes, $840 \mathrm{~cm}^{-1}$ ), and a signal for the carbonyl groups $(-\mathrm{C}=\mathrm{O})$ of urethane linkages $\left(1740 \mathrm{~cm}^{-1}\right)$ was generated, as indicated in Fig. 2c.

\section{2. $T_{g}$ analyses}

Table 2 presents the data from the thermal analyses of the various cured PU/DGEBA-g-IPNs. The values of $T_{\mathrm{g}}$ decreased, relative to that of neat DGEBA resin $\left(T_{\mathrm{g}}=105.07^{\circ} \mathrm{C}\right)$, upon increasing the PU content in DGEBA.

Table 2

Glass transition temperatures of various PU(PBA series)/ DGEBA-g-IPNs systems determined using differential scanning calorimetry (DSC)

\begin{tabular}{lcc}
\hline System & PU content $(\mathrm{wt} \%)$ & $T_{\mathrm{g}}\left({ }^{\circ} \mathrm{C}\right)$ \\
\hline Neat DGEBA & 0 & 105.07 \\
PU(PBA 700)/DGEBA-g-IPNs & 19.42 & 96.95 \\
& 22.54 & 83.79 \\
& 25.43 & 78.80 \\
PU(PBA 1000)/DGEBA-g-IPNs & 22.34 & 83.62 \\
& 25.24 & 77.74 \\
PU(PBA 2000)/DGEBA-g-IPNs & 27.93 & 58.63 \\
& 30.71 & 56.79 \\
& 33.05 & 47.22 \\
\end{tabular}

Takes the PU (PBA 700)/DGEBA-g-IPN system as example, the value of $T_{\mathrm{g}}$ decreased clearly upon increasing the PU content. At a PU content of $25.43 \mathrm{wt} \%$ in PU (PBA 700)/DGEBA-g-IPN, the glass transition occurred at $78.8^{\circ} \mathrm{C}$, which is $26^{\circ} \mathrm{C}$ lower than that of neat DGEBA. Polyurethane reacted with the pendent hydroxyl group on the side chains of DGEBA and existed with good compatibility in the PU/DGEBA-g-IPN structures on the molecular scale; thus, the low value of $T_{\mathrm{g}}$ and the soft properties of polyurethane affected the DGEBA resin to a great extent to cause the decreased values of $T_{\mathrm{g}}[17]$.

When comparing the 25.43-wt\%-PU (PBA 700)/ DGEBA-g-IPN and 25.24-wt\%-PU (PBA 1000)/ DGEBA-g-IPN samples, i.e., those possessing different polyols but the same polyurethane content in Table 2. We found that the decrements of the values of $T_{\mathrm{g}}$ were almost the same. This result suggests that the polyurethane content in a PU/DGEBA-gIPN system is the most important factor affecting the value of $T_{\mathrm{g}}$.

Each of the nine sets of PU (PBA series)/ DGEBA-g-IPNs exhibited a characteristic shift toward a low value of $T_{\mathrm{g}}$ (below $100{ }^{\circ} \mathrm{C}$ ). The most dramatic example was that of the $35.20-\mathrm{wt} \%$-PU (PBA 2000)/DGEBA-g-IPN, whose glass transition temperature decreased by more than $70^{\circ}$ relative to that of the neat DGEBA resin.

\subsection{Mechanical properties of $P U$ \\ (PBA series)/DGEBA-g-IPNs}

Table 3 lists the mechanical properties of various PU(PBA series)/DGEBA-g-IPN systems, included their tensile strengths, Izod impact strengths, bending strengths, and shear strengths.

Table 3

Mechanical properties of various PU(PBA series)/DGEBA-g-IPNs systems

\begin{tabular}{|c|c|c|c|c|c|c|}
\hline & $\begin{array}{l}\text { PU content } \\
(\mathrm{wt} \%)\end{array}$ & $\begin{array}{l}\text { Tensile } \\
\text { strength }(\mathrm{MPa})\end{array}$ & $\begin{array}{l}\text { Elongation } \\
(\%)\end{array}$ & $\begin{array}{l}\text { Izod-impact } \\
\text { strength }(\mathrm{J} / \mathrm{m})\end{array}$ & $\begin{array}{l}\text { Bending } \\
\text { strength }(\mathrm{MPa})\end{array}$ & $\begin{array}{l}\text { Shear strength } \\
(\mathrm{MPa})\end{array}$ \\
\hline Neat DGEBA & 0 & 50.35 & 5.6 & 6.33 & 34.64 & 0.49 \\
\hline $\begin{array}{c}\text { PU(PBA } 700 \text { Series)/ } \\
\text { DGEBA-g-IPNs }\end{array}$ & $\begin{array}{l}19.42 \\
22.54 \\
25.43\end{array}$ & $\begin{array}{l}77.68 \\
80.11 \\
81.47\end{array}$ & $\begin{array}{l}8.4 \\
8.8 \\
9.1\end{array}$ & $\begin{array}{l}9.05 \\
9.35 \\
9.63\end{array}$ & $\begin{array}{l}31.11 \\
25.30 \\
24.77\end{array}$ & $\begin{array}{l}0.28 \\
0.21 \\
0.19\end{array}$ \\
\hline $\begin{array}{c}\text { PU(PBA } 1000 \text { Series }) / \\
\text { DGEBA-g-IPNs }\end{array}$ & $\begin{array}{l}22.34 \\
25.24 \\
27.93\end{array}$ & $\begin{array}{l}73.43 \\
75.65 \\
75.46\end{array}$ & $\begin{array}{l}9.1 \\
9.3 \\
9.7\end{array}$ & $\begin{array}{l}8.63 \\
8.60 \\
8.07\end{array}$ & $\begin{array}{l}31.03 \\
27.60 \\
18.23\end{array}$ & $\begin{array}{l}0.21 \\
0.21 \\
0.20\end{array}$ \\
\hline $\begin{array}{c}\text { PU(PBA } 2000 \text { Series }) / \\
\text { DGEBA-g-IPNs }\end{array}$ & $\begin{array}{l}30.71 \\
33.05 \\
35.20\end{array}$ & $\begin{array}{l}67.77 \\
71.11 \\
71.71\end{array}$ & $\begin{array}{l}9.3 \\
9.5 \\
9.6\end{array}$ & $\begin{array}{l}6.81 \\
6.58 \\
6.58\end{array}$ & $\begin{array}{l}24.16 \\
16.49 \\
14.36\end{array}$ & $\begin{array}{l}0.18 \\
0.16 \\
0.16\end{array}$ \\
\hline
\end{tabular}




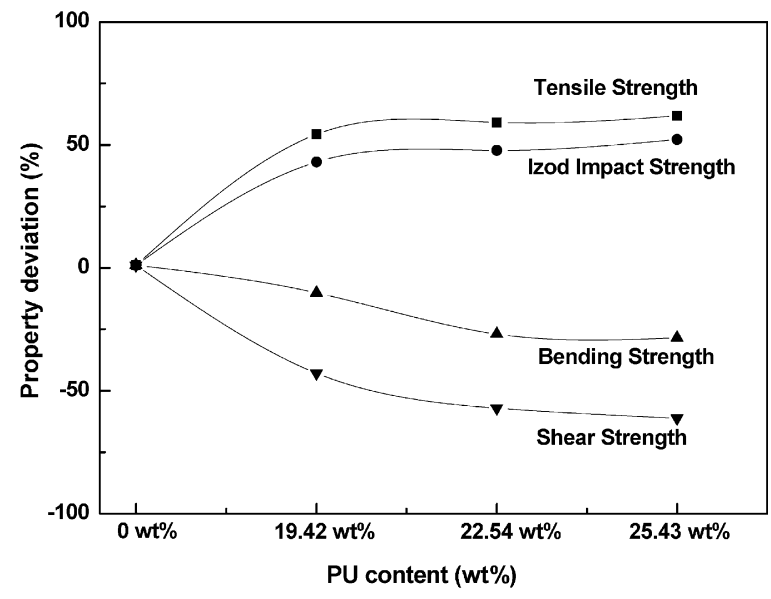

Fig. 3. Mechanical properties of various PU contents in PU(PBA 700)/DGEBA-grafted-IPN system.

As presented in Fig. 3, the horizontal coordinate represents the polyurethane content added in the PU/DGEBA-g-IPN systems and the vertical coordinate represents the mechanical property retention $(\%)$ relative to that of the neat DGEBA resin. The values of the tensile and Izod impact strengths increased upon increasing the polyurethane content in the PU/DGEBA-g-IPN systems, but the values of the bending and shear strengths displayed opposite trends. In the sample containing a $25.43-\mathrm{wt} \%$ polyurethane content in the PU/DGEBA-g-IPN system, the improvements to the tensile strength and Izod impact strength were $62 \%$ and $51 \%$ and the decrements to the bending and shear strength were $28 \%$ and $61 \%$, respectively, relative to that of the neat DGEBA resin. The tensile and Izod impact strengths of the PU/DGEBA-g-IPNs increased upon increasing the PU content. This behavior is due to the covalent chemical bonding between the PU and DGEBA networks and, possibly, permanent interpenetration and entanglement between the PU and DGEBA networks [18]. As a result, the polyurethane was dispersed in the PU/DGEBA-g-IPN system on the molecular scale; the cross-linking density between PU and DGEBA and the dispersion of polyurethane in the PU/DGEBA-g-IPN systems clearly enhanced the tensile strength and Izod impact strength. The low value of $T_{\mathrm{g}}$ and the soft properties of polyurethane also affected the DGEBA resin to a great extent, causing the PU/DGEBA-g-IPNs to become more flexible than neat DGEBA; as a result, the bending and shear strengths of the PU/DGEBA-g-IPNs decreased upon increasing the PU (PBA series) content, as listed in Table 3.

When comparing the 25.43-wt\%-PU (PBA 700)/ DGEBA-g-IPN and 25.24-wt\%-PU (PBA 1000)/ DGEBA-g-IPN samples, i.e., those possessing different polyols but the same polyurethane content in Table 3. The tensile and Izod impact strength all decreased upon increasing the molecular weight of the PBA polyol in PU/DGEBA-g-IPN systems, and the property deviations of bending and shear strength were lower in smaller molecular weight than larger molecular weight of polyol in PU/ DGEBA-g-IPN systems. This is because: (a) more hard segments existed in smaller polyol molecular weight (PBA 700) than larger polyol molecular weight (PBA 1000 and 2000) in the same PU content. (b) the cross-linking density, permanent interpenetration, and entanglement extents between the PU and DGEBA network would be enhanced in smaller polyol molecular weight (PBA 700) than larger polyol molecular weight (PBA 1000 and 2000) in PU/DGEBA-g-IPN systems $[19,20]$ in the same PU content.

\subsection{Mechanical properties of various composites}

Table 4 lists the mechanical properties - including tensile strength, tensile modulus, elongation, and falling-weight impact strength - of various untreated-UHMWPE- and aramid-fiber-reinforced composite materials; Table 5 lists the corresponding properties of the various plasma-treated UHMWPE fiber-reinforced composite materials. Figs. 5-7 compare the effects of various factors - i.e., the degree of plasma treatment, the polyurethane content, and the type of polyol in the DGEBA matrix of a composite - on the mechanical properties. The tensile moduli of two packing composites (unidirectional and cross-ply fiber reinforced composites) were measured by determining the slope of the stressstrain plot from $0.1 \%$ to $0.5 \%$ strain, as shown in Fig. 4. In this range, the stress-strain curves of these two composite specimens had almost identical slopes. Thus, the tensile moduli of the two composite specimens had the same. Nevertheless, the ultimate strength and elongation of these two composites were quite different.

Fig. 5 presents the mechanical properties of the UHMWPE fiber/DGEBA composites (packing angle: $0^{\circ}$ ) with respect to whether or not the UHMWPE fibers had been subjected to plasma treatment. The tensile strengths, tensile moduli, 
Table 4

Mechanical properties of various untreated-UHMWPE-fiber- and aramid-fiber-reinforced composites

\begin{tabular}{|c|c|c|c|c|c|c|c|c|c|c|c|}
\hline \multirow[t]{2}{*}{ Composite system } & \multirow[t]{2}{*}{$\begin{array}{l}\text { PU content } \\
(w t \%)\end{array}$} & \multicolumn{2}{|c|}{$\begin{array}{l}\text { Fiber content } \\
(w t \%)\end{array}$} & \multicolumn{2}{|c|}{$\begin{array}{l}\text { Tensile strength } \\
(\sigma, \mathrm{MPa})\end{array}$} & \multicolumn{2}{|c|}{$\begin{array}{l}\text { Tensile modulus } \\
(\mathrm{GPa})\end{array}$} & \multicolumn{2}{|c|}{$\begin{array}{l}\text { Elongation } \\
(\%)\end{array}$} & \multicolumn{2}{|c|}{$\begin{array}{l}\text { Falling weight impact } \\
\text { strength }(\mathrm{J} / \mathrm{mm})\end{array}$} \\
\hline & & $\left(0^{\circ}\right)$ & $\left(0^{\circ}, 90^{\circ}\right)$ & $\left(0^{\circ}\right)$ & $\left(0^{\circ}, 90^{\circ}\right)$ & $\left(0^{\circ}\right)$ & $\left(0^{\circ}, 90^{\circ}\right)$ & $\left(0^{\circ}\right)$ & $\left(0^{\circ}, 90^{\circ}\right)$ & $\left(0^{\circ}\right)$ & $\left(0^{\circ}, 90^{\circ}\right)$ \\
\hline UHMWPE fiber/DGEBA & 0 & 33.1 & 32.2 & 535.4 & 375.4 & 8.6 & 8.6 & 20.8 & 14.0 & 40.3 & 51.6 \\
\hline Aramid fiber/dgeba & 0 & 33.5 & 31.5 & 524.4 & 315.0 & 10.9 & 9.4 & 4.8 & 4.9 & 17.3 & 21.1 \\
\hline UHMWPE fiber/pu(pba 700)/ & 19.42 & 34.4 & 32.4 & 557.6 & 411.8 & 8.7 & 8.7 & 21.0 & 14.9 & 41.8 & 57.8 \\
\hline \multirow[t]{2}{*}{ DGEBA } & 22.54 & 34.2 & 34.2 & 645.9 & 424.7 & 8.9 & 8.8 & 21.1 & 15.0 & 44.7 & 67.3 \\
\hline & 25.43 & 33.9 & 32.9 & 669.0 & 435.3 & 8.9 & 8.8 & 21.3 & 15.7 & 45.1 & 86.9 \\
\hline $\begin{array}{l}\text { UHMWPE fiber/pu(pba 1000)/ } \\
\text { DGEBA }\end{array}$ & 22.34 & 33.7 & 33.4 & 683.8 & 455.5 & 9.1 & 9.0 & 21.7 & 15.9 & 44.3 & 94.4 \\
\hline $\begin{array}{l}\text { UHMWPE fiber/pu(pba 2000)/ } \\
\text { DGEBA }\end{array}$ & 30.71 & 34.5 & 33.5 & 709.6 & 498.2 & 9.2 & 9.1 & 21.9 & 16.4 & 43.8 & 85.9 \\
\hline
\end{tabular}

Table 5

Mechanical properties of various plasma-treated UHMWPE fiber-reinforced composites

\begin{tabular}{|c|c|c|c|c|c|c|c|c|c|c|c|}
\hline \multirow[t]{2}{*}{ Composite system } & \multirow[t]{2}{*}{$\begin{array}{l}\text { PU content } \\
(\mathrm{wt} \%)\end{array}$} & \multicolumn{2}{|c|}{$\begin{array}{l}\text { Fiber content } \\
(w t \%)\end{array}$} & \multicolumn{2}{|c|}{$\begin{array}{l}\text { Tensile strength } \\
(\sigma \mathrm{MPa})\end{array}$} & \multicolumn{2}{|c|}{$\begin{array}{l}\text { Tensile modulus } \\
(\mathrm{GPa})\end{array}$} & \multicolumn{2}{|c|}{$\begin{array}{l}\text { Elongation } \\
(\%)\end{array}$} & \multicolumn{2}{|c|}{$\begin{array}{l}\text { Falling weight impact } \\
\text { strength }(\mathrm{J} / \mathrm{mm})\end{array}$} \\
\hline & & $\left(0^{\circ}\right)$ & $\left(0^{\circ}, 90^{\circ}\right)$ & $\left(0^{\circ}\right)$ & $\left(0^{\circ}, 90^{\circ}\right)$ & $\left(0^{\circ}\right)$ & $\left(0^{\circ}, 90^{\circ}\right)$ & $\left(0^{\circ}\right)$ & $\left(0^{\circ}, 90^{\circ}\right)$ & $\left(0^{\circ}\right)$ & $\left(0^{\circ}, 90^{\circ}\right)$ \\
\hline UHMWPE fiber/DGEBA & 0 & 34.4 & 35.1 & 553.8 & 394.9 & 8.7 & 8.7 & 12.8 & 10.7 & 40.3 & 51.1 \\
\hline UHMWPE fiber/PU(PBA 700)/ & 19.42 & 34.9 & 35.4 & 583.6 & 414.0 & 9.0 & 8.8 & 13.1 & 11.1 & 41.3 & 53.7 \\
\hline \multirow[t]{2}{*}{ DGEBA } & 22.54 & 34.2 & 35.7 & 668.9 & 471.2 & 9.4 & 9.1 & 13.4 & 11.4 & 42.9 & 65.0 \\
\hline & 25.43 & 33.9 & 34.9 & 687.9 & 532.3 & 9.9 & 9.7 & 13.9 & 11.9 & 45.0 & 88.9 \\
\hline $\begin{array}{l}\text { UHMWPE Fiber/PU(PBA 1000)/ } \\
\text { DGEBA }\end{array}$ & 22.34 & 34.1 & 34.7 & 707.9 & 538.2 & 10.1 & 9.9 & 14.1 & 12.1 & 44.8 & 89.7 \\
\hline $\begin{array}{l}\text { UHMWPE Fiber/PU(PBA 2000)/ } \\
\text { DGEBA }\end{array}$ & 30.71 & 33.5 & 35.5 & 728.6 & 554.1 & 10.2 & 10.0 & 14.4 & 12.4 & 44.2 & 86.4 \\
\hline
\end{tabular}




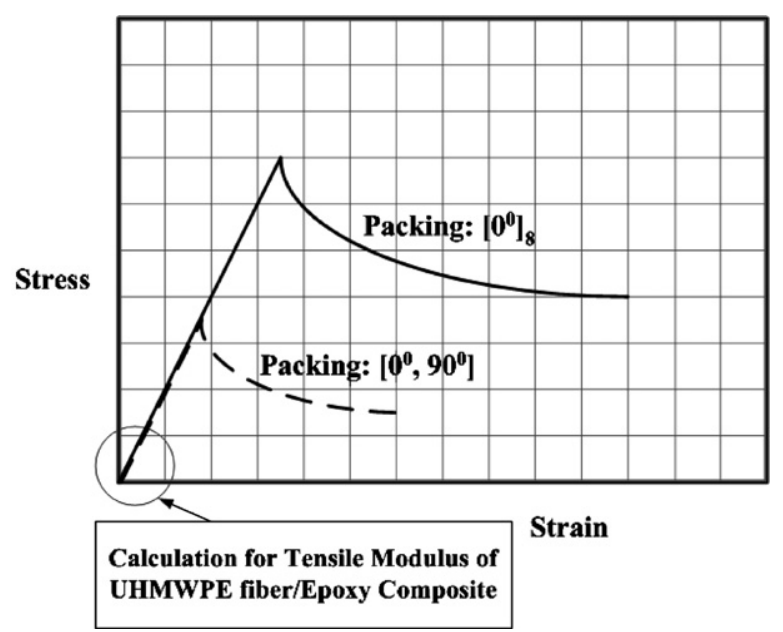

Fig. 4. Representative stress/strain curves for unidirectional and cross-ply UHMWPE fiber reinforced DGEBA composites.

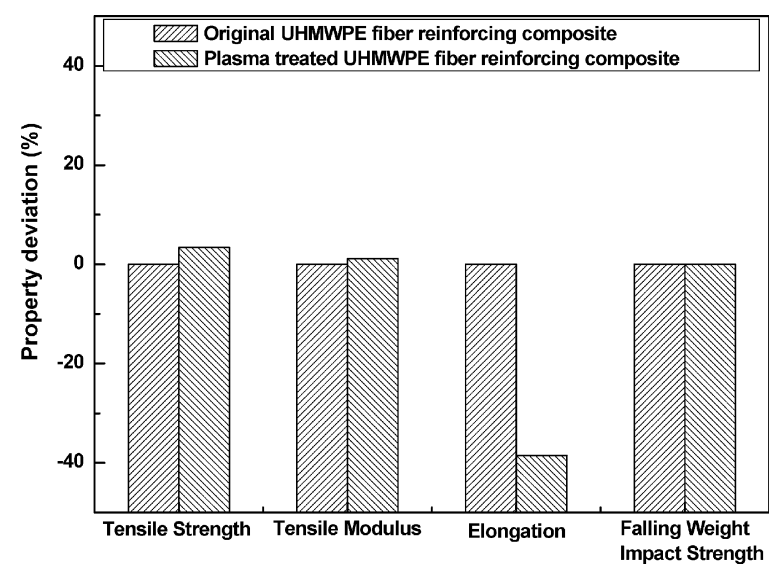

Fig. 5. Effect of the plasma treatment on the mechanical properties of UHMWPE fiber/DGEBA composites at a unidirectional packing angle.

and falling-weight impact strengths of these two sets of composites were nearly identical, but the elongations were different. These mechanical properties were affected by two competing effects: (a) degradation of the fiber's strength through scission and dehydrogenation on the UHMWPE fiber surface and (b) improved interfacial adhesion between the UHMWPE fiber and the DGEBA matrix. It seems reasonable to suggest that the tensile strengths, tensile moduli, and falling-weight impact strengths of these two composites were nearly identical because these two competing effects cancelled each other out. With respect to the elongation, that of the plasma-treated UHMWPE fiber composite dec-

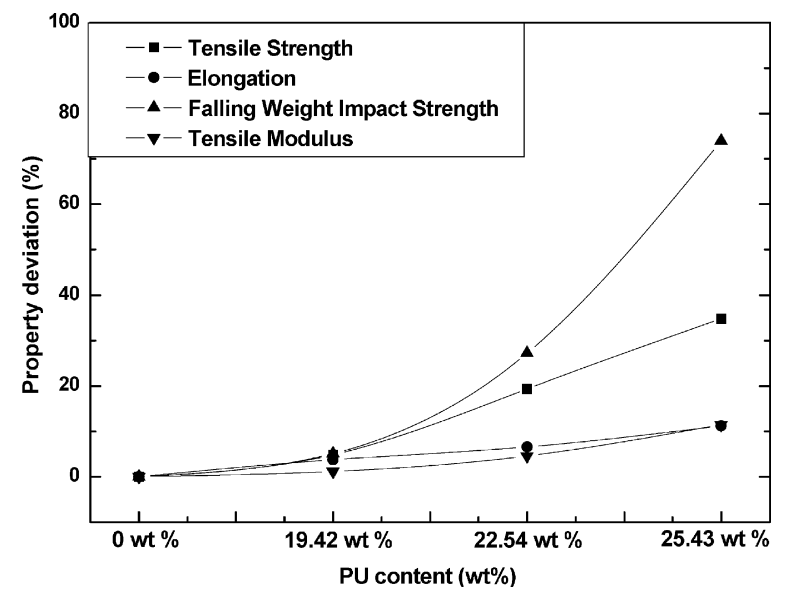

Fig. 6. Mechanical properties of various plasma-treated UHMWPE fiber/PU(PBA 700 series)/DGEBA-grafted-IPN composites at perpendicular packing angles.

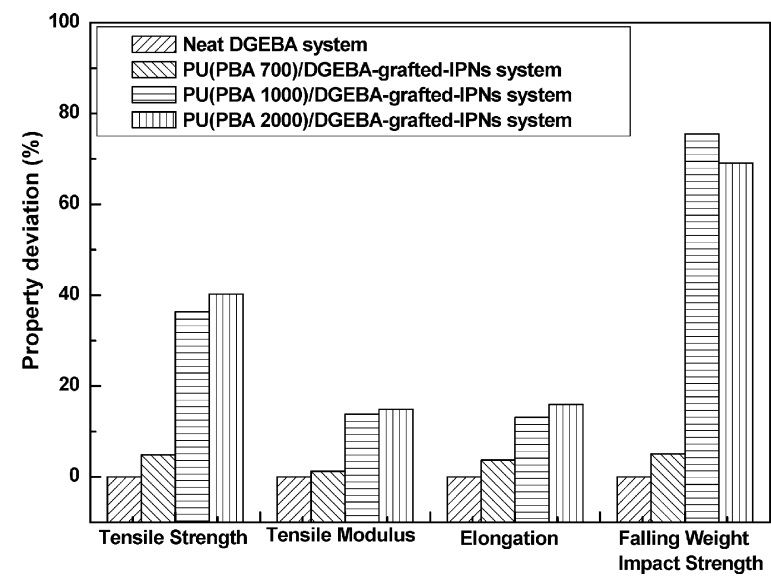

Fig. 7. Effect of the molecular weight of polyol in the PU on the mechanical properties of various original UHMWPE fiberreinforced composites at perpendicular packing angles.

reased significantly (more than $40 \%$ ) relative to that of the untreated UHMWPE fiber-reinforced composite [cf. Fig. 8b-c]. The UHMWPE fiber is a non-polar material; consequently, its degree of interfacial adhesion with the polar DGEBA matrix was very poor. Indeed, the composite underwent a pull-out fracture mechanism during tensile testing, as the SEM image in Fig. 8b indicates. After plasma treatment of the UHMWPE fiber surface, the interfacial adhesion within composite increased significantly because of the presence of polar functional groups on the surface of the resulting fibers; thus, the elongation decreased accordingly, as indicated in Fig. 8c. 

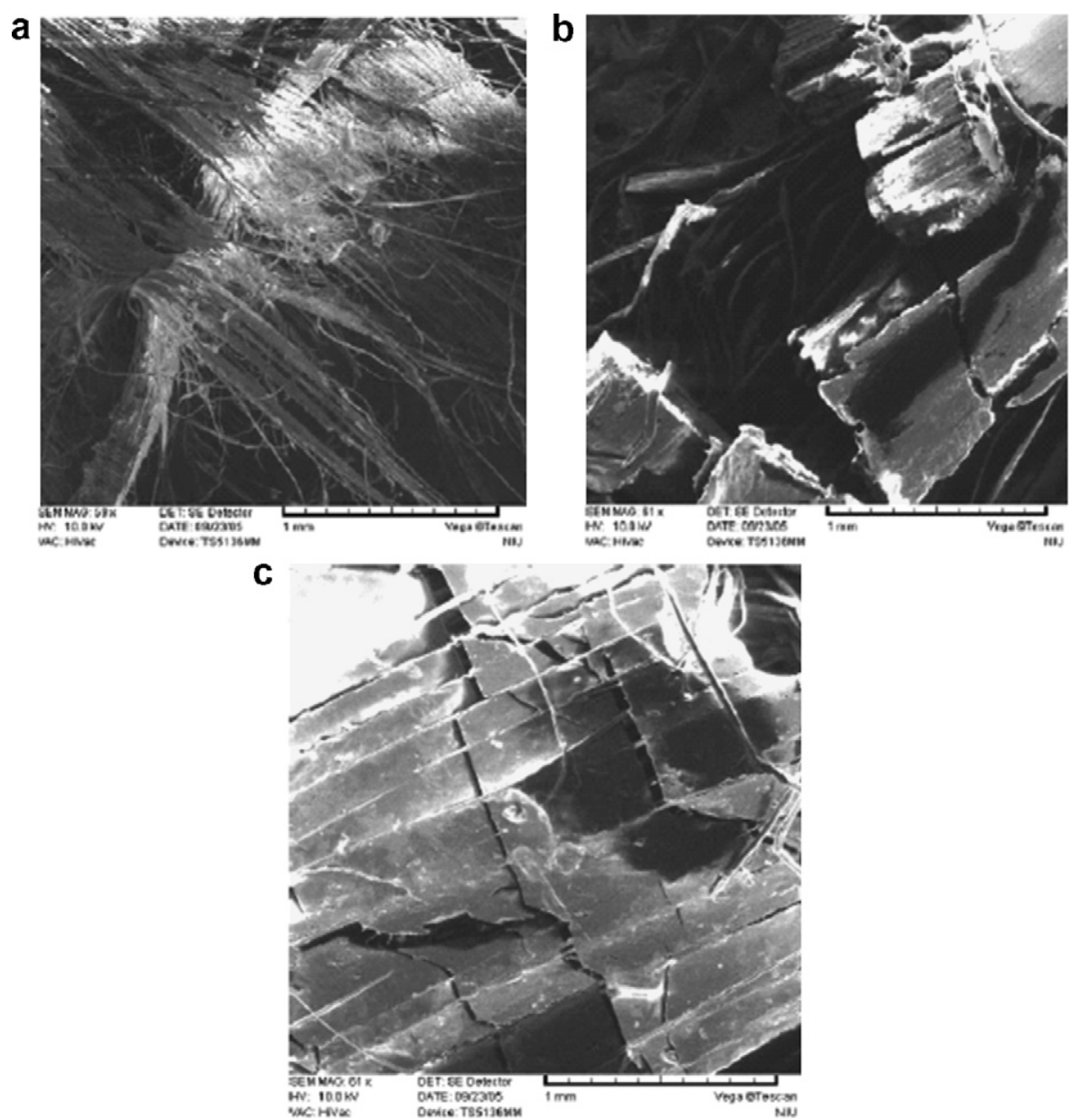

Fig. 8. SEM images of various side-view fracture surfaces: (a) aramid fiber/DGEBA composite; (b) original UHMWPE fiber/DGEBA composite; (c) plasma-treated UHMWPE fiber composite.

Fig. 6 displays the mechanical properties of the UHMWPE fiber/PU/DGEBA-g-IPN composites (with packing angle: $0^{\circ}, 90^{\circ}$ ) as a function of the polyurethane content in the matrix of the composite. The tensile strengths, tensile moduli, elongations, and falling-weight impact strengths all increased significantly upon increasing the polyurethane content in the matrix of composite; the effects on the tensile strengths and falling-weight impact strengths were particularly dramatic. In the sample containing a $25.43-\mathrm{wt} \%$ polyurethane content in the matrix of the plasma-treated UHMWPE fiber/ PU/DGEBA-g-IPN composite, the improvements to the tensile strength and falling-weight impact strength were $35 \%$ and $74 \%$, respectively, relative to that of the plasma-treated UHMWPE fiber reinforced neat DGEBA composite. These dramatic changes are due to two factors: (a) Covalent chemical bonding, permanent interpenetration, and entanglement between the PU prepolymer and the DGEBA networks meant that the PU prepolymer was dispersed very well within the PU/DGEBA-gIPN systems; thus, the cross-linking density between the PU prepolymer and DGEBA and the dispersion of polyurethane in the PU/DGEBA-g-IPN system were both enhanced. (b) Plasma treatment improved the degree of interfacial adhesion between the UHMWPE fibers and the DGEBA matrix. Nevertheless, these factors did not significantly affect the intrinsic properties, i.e., the elongations and tensile moduli, of the composites comprising plasmatreated UHMWPE fibers and PU/DGEBA-g-IPN matrices.

In the research, two effects (PU content and packing-way) were discussed in the falling weight impact strength of UHMWPE fiber/PU(PBA 
series)/DGEBA-g-IPNs composites. Firstly, the cross-ply laminates of composites were compared with the unidirectional laminates of composites to examine the effect of packing-way in the falling weight impact strength. The cross-ply packing-way exhibited higher values than unidirectional packing-way composites around whole the UHMWPE fiber/PU(PBA series)/DGEBA-g-IPNs systems. Secondly, we arranged three polyurethane wt $\%$ (19.42, 22.54 , and $25.43 \mathrm{wt} \%$ ) to compare the effect of the polyurethane content in UHMWPE fiber/PU(PBA 700)/DGEBA-g-IPNs composites in the falling weight impact strength. In such a high speed impact testing, the existence of PU(PBA 700) in PU/ DGEBA-g-IPNs systems exhibited higher values of falling weight impact strength relative to that of the neat DGEBA resin, and the more the PU content added in PU/DGEBA-g-IPNs systems, the higher values of falling weight impact strength was obtained. The presence of the soft structure polyurethane aided the formation of graft-IPN structures, and increased the toughness of the UHMWPE fiber/PU/DGEBA-g-IPN composites for the highshear-rate fracturing.

Fig. 7 presents the mechanical properties of the UHMWPE fiber/PU/DGEBA-g-IPN composites (packing angle: $0^{\circ}, 90^{\circ}$ ) as a function of the type of polyol in the polyurethane used in the matrix of the composite. The three kinds of polyol-containing polyurethanes were added at the same equivalent ratio of $\mathrm{PU}(\mathrm{PBA}$ series), but with different PU contents $(19.42 \mathrm{wt} \%, 22.34 \mathrm{wt} \%$, and $30.71 \mathrm{wt} \%$ for PU/DGEBA-g-IPN systems based on PBA 700, 1000 , and 2000 series). It means that the contents of the hard segments were identical, but with different soft segments around these three PU/DGEBAg-IPN systems. The tensile strengths, tensile moduli, elongations, and falling-weight impact strengths all increased upon increasing the molecular weight of the PBA polyol in the polyurethane within the PU/DGEBA-g-IPN matrix of the composite; the effects on the tensile strength and falling-weight impact strength were especially dramatic. When the molecular weight of the PBA polyol in the polyurethane was larger than 1000, the falling-weight impact strength of the UHMWPE fiber/PU/ DGEBA-g-IPN was improved by more than $65 \%$ relative to that of the UHWMPE fiber reinforced neat DGEBA composite. Again, the intrinsic properties, i.e., the elongation and tensile modulus, did not change significantly among the various composites. The results about the effect of the type of polyol in the DGEBA matrix of a composite was contrary to the PU/DGEBA-g-IPN resin systems, the effect of the PU content was more important than the effect of molecular weight of polyol in the DGEBA matrix of a composite in the presentation of mechanical properties. Although the three kinds of polyol-containing polyurethane were added at the same PU(PBA series) equivalent ratio in the PU/DGEBA-g-IPN systems, the PU content of the PU(PBA 700)/DGEBA-g-IPN system $(19.42 \mathrm{wt} \%)$ was lower than the PU(PBA 1000) and PU(PBA 2000)/DGEBA-g-IPN systems [22.34 and $30.71 \mathrm{wt}^{\circ} \%$ ].

As listed in Table 4, the tensile strengths and tensile moduli of the composites containing UHMWPE fibers as reinforcement materials were nearly identical to those of the aramid fiber-reinforced composite, but the elongations and falling-weight impact strengths of these two composites were obviously different. The SEM images in Fig. 8a-c help to explain the differences between the UHMWPE and aramid fibers. Aramid fiber is a polar fiber that adheres well to the polymer matrix in the composite because of attractive hydrogen bonding and other polar interactions. During tensile testing, the aramid fiber did not undergo a pull-out fracture mechanism; its elongation was based on stretching and elastic deformation by itself in the composite, such that the elongation of the aramid fiber-reinforced composite was lower than that of the UHMWPE fiber-reinforced composite. Thus, these two kinds of fibers are suited to applications in different fields.

Because the polyurethane content and the type of polyol in the polyurethane within a PU/DGEBA-gIPN matrix both affected the mechanical properties of the composites greatly, we manufactured UHMWPE fiber/PU composites containing pure polyurethane $(100 \%)$ with a soft polyol (PPG 2000) within the polymer matrix and subjected them to tests of their bulletproof nature. Table 6 lists the results of bulletproof testing of these two kinds of fiber-reinforced polyurethane composites. The UHMWPE fiber/PU composite exhibited bulletproof properties similar to those of the aramid fiber/PU composite, despite the poor thermal resistance properties of the UHMWPE fiber. From standard testing using the NIJ 0108.01 IIA method at a thickness of $5 \mathrm{~mm}$, the UHMWPE fiber/PU composite and the aramid fiber/PU composite both exhibited bulletproof properties; in this case, the number of penetrating layers of the UHMWPE fiber/PU composite (35 layers) was greater than that 
Table 6

Bulletproof tests of UHMWPE fiber/PU composites and aramid fiber/PU composites

\begin{tabular}{|c|c|c|c|c|}
\hline System & $\begin{array}{l}\text { Standard testing } \\
\text { method }\end{array}$ & $\begin{array}{l}\text { Layers passed } \\
\text { through }\end{array}$ & Results & Photographs \\
\hline
\end{tabular}

\section{$5 \mathrm{~mm}$ UHMWPE fiber/polyurethane composite}

$5 \mathrm{~mm}$ Aramid fiber/polyurethane composite

\section{$5 \mathrm{~mm}$ UHMWPE fiber/polyurethane composite} $5 \mathrm{~mm}$ Aramid
fiber/polyurethane
composite
NIJ 0108.01 IIA (380 m/s)

NIJ 0108.01 IIIA (452 m/s)

48

NIJ 0108.01 IIIA $(436 \mathrm{~m} / \mathrm{s})$

34

NIJ 0108.01 IIIA (499 m/s)

67

Not penetrated fiber/polyurethane composite

Not penetrated
NIJ 0108.01 IIIA (490 m/s)

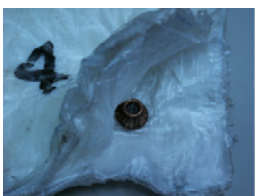

Not penetrated

35
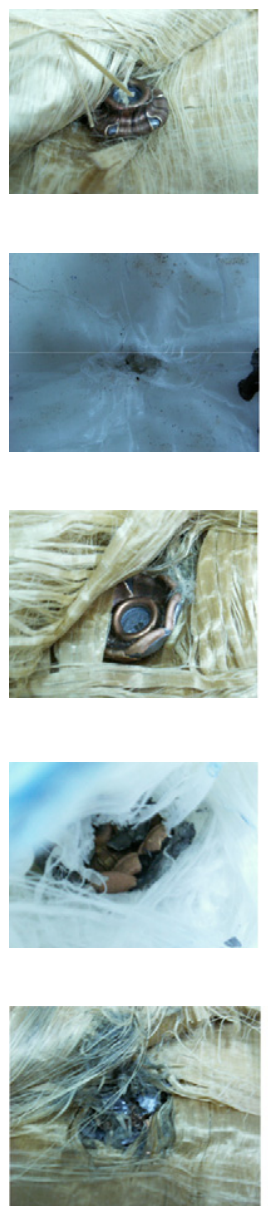
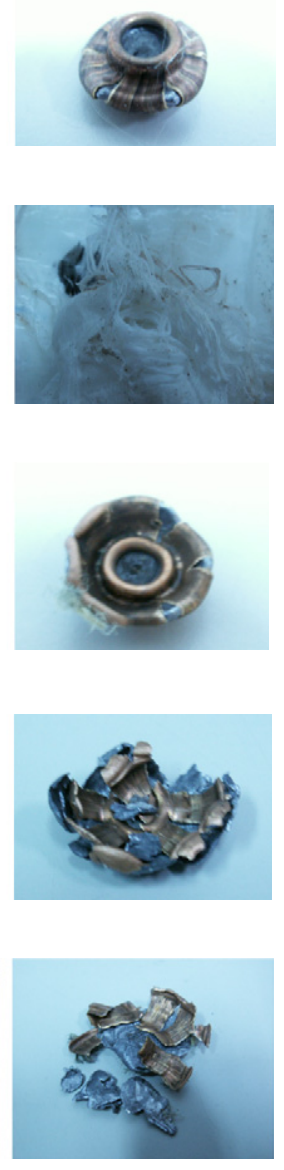

of the aramid fiber/PU composite (23 layers). From standard tests using the NIJ 0108.01 IIIA method at a thickness of $5 \mathrm{~mm}$, the UHMWPE fiber/PU composite did not exhibit bulletproof properties, whereas the aramid fiber/PU composite did. In contrast, standard testing using the NIJ 0108.01 IIIA method at a thickness of $10 \mathrm{~mm}$ indicated that the UHMWPE fiber/PU composite displayed bulletproof properties similar to those of the aramid
fiber/PU composite; in this case, the number of penetrating layers of the UHMWPE fiber/PU composite (67 layers) was nearly equal to that of the aramid fiber/PU composite (64 layers).

\section{Conclusion}

The low values of $T_{\mathrm{g}}$ and soft characteristics of polyurethanes within PU/DGEBA-g-IPN systems 
cause them to be more flexible than neat DGEBA. Nine sets of PU/DGEBA-g-IPN systems exhibited reduced values of $T_{\mathrm{g}}$ and improved tensile and Izod impact strengths relative to those of neat DGEBA. The soft properties of the polyurethanes also caused the bending and shear strengths of the PU/ DGEBA-g-IPN systems to decrease upon increasing the PU content.

The mechanical properties of the UHMWPEfiber- and aramid-fiber-reinforced composites were different, suggesting that these two kinds of fibers were suited to applications in different fields.

Plasma treatment improved the degree of interfacial adhesion between the UHMWPE fibers and the DGEBA matrix, but it decreased the fiber strength. As a result, the plasma-treated UHMWPE fiberreinforced composites exhibited nearly identical mechanical properties as those of the corresponding untreated UHMWPE fiber-reinforced composites, with the exception of their quite different elongation properties.

The content and molecular weight of the polyol in the polyurethane within the PU/DGEBAg-IPN matrix had a significant effect on the tensile strength, tensile modulus, elongation, and falling-weight impact strength of the resultant composites.

From standard tests using the NIJ 0108.01 IIIA method at sample thicknesses of $10 \mathrm{~mm}$, the UHMWPE fiber/PU composite exhibited bulletproof properties that were comparable to those of the aramid fiber/PU composite; in this test, the number of penetrating layers of each composite was nearly the same.

\section{Acknowledgements}

We are grateful to the following departments for allowing us to borrowing various pieces of equipment: the Department of Chemical Engineering and Materials Engineering, National I-Lan University (Tescan 5136 MM SEM), the Department of Polymer Engineering, National Taiwan University of Science and Technology (fallingweight tester), and the Department of Chemical and Materials Engineering, Tam-Kang University (plasma treatment apparatus). This study was supported financially by the National Science Council of Taiwan, under Contract No. NSC 92-2622-E011-020.

\section{References}

[1] Lin JM, Ma CCM, Tai NH, Chang WC, Tsai CC. Carbon fiber reinforced phenolic resin/silica ceramer compostesprocessing, mechanical and thermal properties. Polym Compos 2000;21:305-11.

[2] Hung AYC, Wang FY, Yeh SR, Chen WJ, Ma CCM. Carbon/carbon composites derived from poly(ethylene oxide)-modified novolac-type phenolic resin:microstructure and physical, and morphological properties. J Appl Polym Sci 2002;84:1609-19.

[3] Wu HD, Ma CCM, Lin JM. Processability and properties of phenoxy resin toughened phenolic resin composites. J Appl Polym Sci 1997;63:911-7.

[4] Ma CCM, Lee CT, Wu HD. Mechanical properties, thermal stability, and flame retardance of pultruded fiber-reinforced poly(ethylene oxide)-toughened novolak-type phenolic resin. J Appl Polym Sci 1998;69:1129-36.

[5] Ma CCM, Tseng HT, Wu HD. Blocked diisocyanate polyester-toughened novolak-type phenolic resin:synthesis, characterization, and properties of composites. J Appl Polym Sci 1998;69:1119-27.

[6] Wang FY, Ma CCM, Wu WJ. Mechanical properties, morphology, and flame retardance of glass fiber-reinforced polyamide-toughened novolac-type phenolic resin. J Appl Polym Sci 1999;73:881-7.

[7] Arnold JJ, Zamora MP, Brennan AB. Characterization of UHMWPE fiber/matrix adhesion by dynamic mechanical spectrometry. Polym Compos 1996;17:332-42.

[8] Pegoretti A, Ashkar M, Migliaresi C, Marom G. Relaxation processes in polyethylene fiber-reinforced polyethylene composites. Compos Sci Technol 2000;60:1181-9.

[9] Han JL, Tseng SM, Mai JH, Hsieh KH. Polyurethanecrosslinked epoxy resins I. Mechanical behavior. Angewandte Makromol Chem 1990;181:193-203.

[10] Debnath S, Ranade R, Wunder SL, Baran GR, Zhang JM, Fisher ER. Chemical surface treatment of ultrahigh molecular weight polyethylene for improved adhesion to methacrylate resins. J Appl Polym Sci 2005;96:1564-72.

[11] Silverstein MS, Breuer O. Relationship between surface properties and adhesion for etched ultra-high-molecularweight polyethylene fibers. Compos Sci Technol 1993; 48:151-7.

[12] Zheng Z, Tang XZ, Shi MW, Zhou G. A study of the influence of controlled corona treatment on UHMWPE fibers in reinforced vinylester composites. Polym Int 2003; 52:1833-8.

[13] Moon SI, Jang J. The effect of the oxygen-plasma treatment of UHMWPE fiber on the transverse properties of UHMWPE fiber/vinylester composites. Compos Sci Technol 1999;59:487-93.

[14] Zhang HP, Sui MW, Zhang JC, Wang SY. Effects of sunshine uv irradiation on the tensile properties and structure of ultrahigh molecular weight polyethylene fiber. J Appl Polym Sci 2003;89:2757-63.

[15] Zheng Z, Tang XZ, Shi MW, Zhou GT. Surface modification of ultrahigh-molecular-weight polyethylene fibers. J Polym Sci Polym Phys 2004;42:463-72.

[16] Shu WY, Lin KF. The effects of additives on curing properties, resin contents, and mechanical properties of graphite/epoxy composites. Polym Compos 1992;13:213-22. 
[17] Han JL, Tseng SM, Mai JH, Hsieh KH. Polyurethanecrosslinked epoxy resins II. Compatibility and morphology. Angew Makromol Chem 1991;184:89-97.

[18] Cassidy EF, Xiao HX, Frisch KC, Frisch HL. Twocomponent interpenetrating polymer networks (IPNs) from polyurethanes and epoxies I. Studies on full IPN, pseudoIPN and graft polymer alloys of polyurethanes and epoxies. J Polym Sci Polym Chem 1984;22: 1839-50.
[19] Hsieh KH, Han JL. Graft interpenetrating polymer networks of polyurethane and epoxy I. Mechanical behavior. J Polym Sci Polym Phys 1990;28:623-30.

[20] Hsieh KH, Han JL. Graft interpenetrating polymer networks of polyurethane and epoxy. II. Toughening mechanism. J Polym Sci Polym Phys 1990;28:783-94. 